\title{
Atık Barajlarındaki Su Kaçaklarının İncelenmesi: Çanakkale Örneği
}

\author{
Investigation of Water Seepage from Tailing Dams, Case of Çanakkale \\ Koray ULAMIŞ $\mathbb{D}$, Recep KILIÇ $\mathbb{D}$ \\ Ankara Üniversitesi, Mühendislik Fakültesi, Jeoloji Mühendisliği Bölümü, Gölbaşı, ANKARA
}

Geliş (Received): 06 Haziran (June) 2017, Düzeltme (Revised): 03 Temmuz (July) 2017, Kabul (Accepted): 05 Temmuz (July) 2017

\begin{abstract}
ÖZ
Maden sahalarında işlenen cevherden artan pasa, atık havuzlarında yüzdürme metodu ile seçilerek depolanmaktadır. Atık rezervuarının planlanmasında taban zemininindeki birimlerin ve gövde inşaatında kullanılacak doğal malzemenin jeoteknik özelliklerinin belirlenmesi, su kaçaklarının önlenmesi amacıyla önemlidir. $\mathrm{Bu}$ çalışmada, Çanakkale ili, Yenice ilçesi, Kalkım beldesi güneyinde işletilmekte olan $\mathrm{Pb}-\mathrm{Zn}$ tesisine ait atık depolama rezervuar alanındaki zeminlerden sızmaların sebepleri araştııılmıştır. Bu amaçla rezervuar alanındaki zeminin yatay ve düşey yöndeki değişimi ile geçirimlilik özellikleri incelenmiştir. Atık alanı çevresinde araştırma çukurları açılarak zeminlerden örselenmiş ve örselenmemiş örnekler alınmıştır. Standart kompaksiyon deneyleri ile zeminlerin optimum su içeriği ve maksimum kuru yoğunluğu tespit edilmiş, sıkıştırılan örneklerin geçirimlilik katsayıları düşen seviyeli permametre ile belirlenmiştir. Rezervuar tabanındaki kilin geçirimlilik ve sıkışma parametreleri açısından ilgili yönetmeliklere uygun olduğu belirlenmiştir. Kil kaplama yapılmadan önce eski dere yatağındaki su drene edilmiş, fakat eski alüvyon kazılmadan üzerine baraj dolgusu inşaa edilmiş olup, su sızmalarının bu seviyeden olduğu belirlenmiştir. Gövdenin doğusundaki dere yatağında sızan su ile taşınmış ağır metaller ve demiroksit çökeltilerine rastlanmıştır. Gövdenin eski alüvyon üzerine gelen yaklaşık $100 \mathrm{~m}$ uzunluğundaki kesimi kaldırılmış, eski alüvyon temizlendikten sonra rezervuar alanında bulunan zemini optimum su içeriği ve maksimum kuru yoğunlukta sıkıştııılarak gövdenin yeniden inşa edilmesine karar verilmiştir. Gövdenin tamamlanıp, rezervuara suyun dolmasından sonra sızıntının kesildiği gözlenmiştir.
\end{abstract}

Anahtar Kelimeler : Atık Barajı, Çanakkale, Çevre, Geçirimlilik, Sıkışma, Sızıntı.

\begin{abstract}
The waste material extracted after ore mining process is floated in the tailing dams within the mining plants. In order to prevent possible water seepage, the geotechnical characteristics of natural building materials of the dams and foundation soils must be determined for the design of reservoir. In this study, the reasons of water seepage from the waste disposal reservoir of Pb-Zn mining plant located at southern Çanakkale, Kalkum town were investigated. In this context, horizontal and vertical distribution and the permeability of the foundation soils at the reservoir areawere determined by trial pits, disturbed/undisturbed sampling and laboratory testing. The optimum water content and maximum dry density of the soils have been tested by standard compaction tests. Moreover, the permeability coefficient of the same soils was tested by falling head permeameter. The clay lining beneath the reservoir is properly compacted based on the related regulations with no permeability problem. However, the seepage from the reservoir is found to be due to the alluvial soils of the stream bed which is not excavated before the construction. Heavy metal and oxidated residual materials were observed in the stream bed. A total length of $100 \mathrm{~m}$ of the embankment located
\end{abstract}


Ulamış, Kılıç

on the alluvial soil was removed. This portion of the embankment was re-compacted using the clayey soils with optimum water content and maximum dry density. The seepage from the embankment is completely prevented after re-compaction with a full reservoir.

Keywords : Tailing Dam, Çanakkale, Environment, Permeability, Compaction, Seepage.

\section{GíRiş}

Cevher zenginleştirme tesislerindeki atık depolama alanlarının amacı, işlenen malzemeden artan pasanın çevreye olumsuz bir etki yaratmadan suda çöktürülerek toplanmasını sağlamaktır. Pasanın çevreye ve yeraltı suyuna olumsuz etkisini önlemek amacı ile atık havuzunun temeli sıkıştırılmış geçirimsiz malzeme ile kaplanmalı ve geçirimsizliği sağlayacak bir baraj gövdesi projelendirilmelidir. Rezervuar temelinin ve gövde malzemesinin sıkıştırılması ile ilgili literatürde çeşitli çalışmalar yapılmıştır (Johnson ve Sallberg, 1960; Hilf, 1975; Cedergren, 1989; Holtz, 1989; TRB, 1990). Rezervuar ve baraj gövdesinden kaynaklanabilecek su kaçakları ve çevresel etkileri de ayrıca incelenmiştir (ICOLD, 1981; TRB, 1990; McGuffey vd., 1990; Dougherty ve Hall, 1995; Sharma ve Busaidi, 2001; Ghobadi vd., 2005; Y1lmaz ve Atmaca, 2006; Kılıç, 2007; Ulamış vd., 2013).

$\mathrm{Bu}$ çalışmada, Çanakkale ili, Kalkım beldesi güneyinde işletilmekte olan $\mathrm{Pb}-\mathrm{Zn}$ cevher zenginleştirme tesisine ait atık depolama rezervuarının temel zemini ile baraj gövdesinin geçirimlilik ve sıkışma özellikleri incelenmiştir. $\mathrm{Bu}$ amaçla inceleme alanında araştırma çukurları açılarak örnekler alınmış ve bu örneklerin geçirimlilik ve sıkışma özellikleri laboratuvarda belirlenmiştir. Arazi incelemelerinde rezervuarın kuzeyinde Han Deresi'nin yan kolu olan bir dere yatağında siyah ve sarımsı atıkların çökelmiş olduğu gözlenmiştir. Rezervuar tabanındaki eski dere yatağının alüvyonlarından sızıntı olduğu zemin profillerine göre belirlenmiş ve önlenmesi için öneriler getirilmiştir.

\section{JEOLOJI}

İnceleme alanı ve çevresindeki birimler; Miyosen yaşlı Kalkım Volkanitleri, Pliyosen yaşlı Akköy formasyonu ve Han Deresi alüvyonlarıdır. Kalkım Volkanitleri, kırmızımsı kahverengi andezit, grimsi yeşil renkli tüf ve aglomeradan oluşur. Akköy formasyonu altta konglomera ile başlayarak, üst kesimlerde birbiri ile geçişli kumtaşı, kiltaşı ve marndan oluşur (Erentöz, 1975; Gözler vd., 1984; Orgün vd., 2005). Han Deresi ve yan kollarında ise çak1l, kum, silt ve kilden oluşan güncel alüvyon yer alır. İnceleme alanında Akköy formasyonu'na (Şekil 1) ait kahverenkli kil içinde yer yer grimsi yeşil kum bantları ve kalınlığı en fazla 1.0 m olan alüvyon bulunmaktadır (Kılıç, 2007). İnceleme alanı ve yakın çevresindeki cevherleşmenin kökeni ve yeraltı modellemesi ile ilgili çalışmalar yapılmıştır (Anıl, 1984; Tufan, 2003; Akıska vd., 2013a, 2013b). 


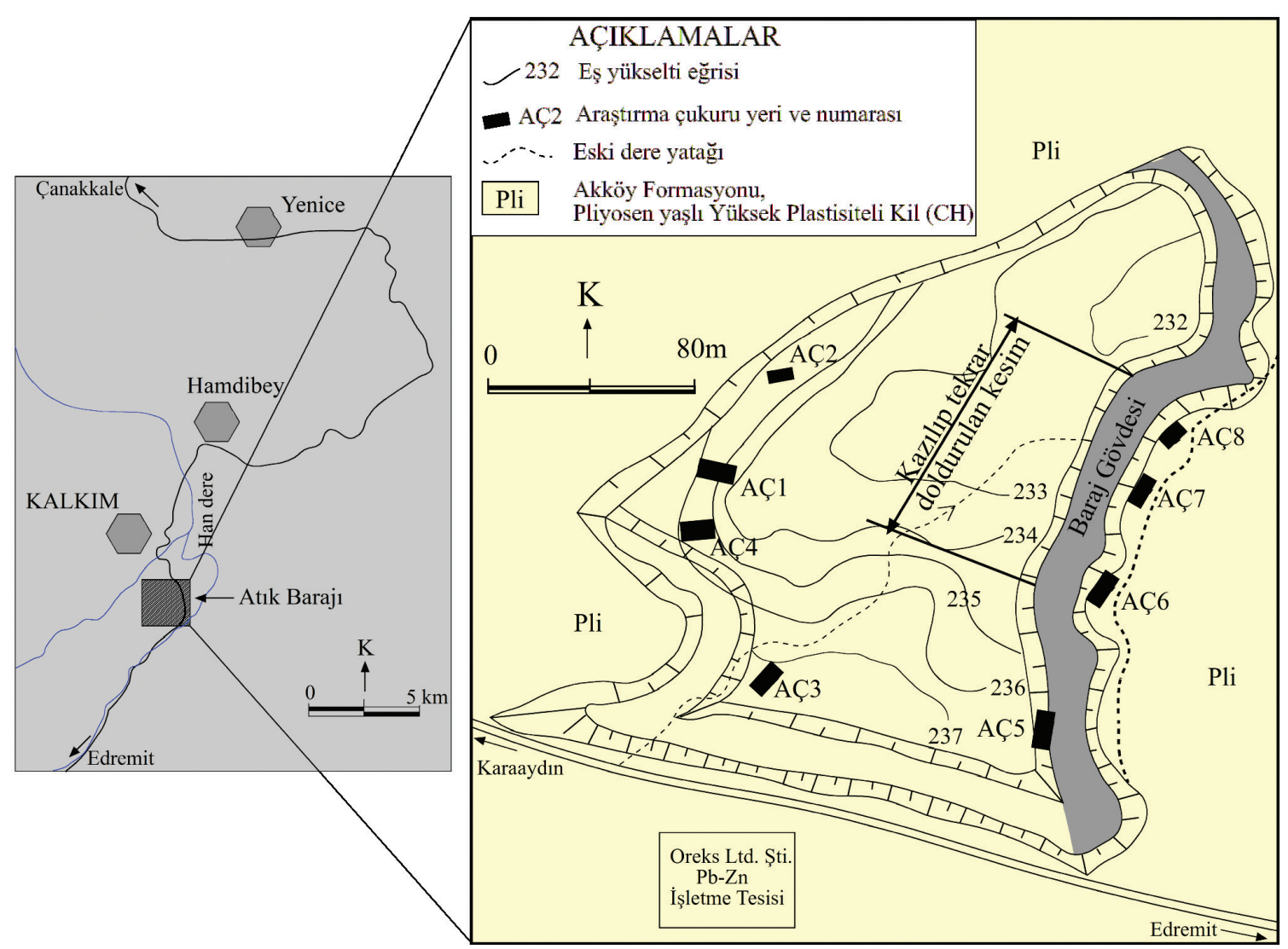

Şekil 1. İnceleme alanının konumu ve jeoloji haritası.

Figure 1. Location and geological map of the study area.

\section{ARAZİ İNCELEMELERI}

İnceleme alanındaki kahverenkli kil ile içindeki kum merceklerinin düşey ve yatay dağılımını belirlemek, yeraltı suyu seviyesini ölçmek, olası su kaçaklarının olduğu seviyeleri belirlemek ve örnek almak amacı ile derinlikleri $5.0 \mathrm{~m}$ ile $8.5 \mathrm{~m}$ arasında değişen 8 adet araştırma çukuru açılmıştır (Şekil 2). Göl alanı batısında açılan çukurlarda en fazla $1.0 \mathrm{~m}$ kalınlıktaki alüvyonun altında yeşilimsi kum bantları içeren kahverenkli kil gözlenmiştir. Kalınlığ 7.5 m’ye varan baraj dolgu malzemesi altında alüvyon ve merceksel kum bantlı kahverengi kil kesilmiştir.

\section{LABORATUVAR İNCELEMELERİ}

Zeminlerin sınıflama, geçirimlilik, sıkışma ve fiziksel özellikleri laboratuvar deneyleri ile belirlenmiştir (TS 1900-1, 2006; ASTM, 2012). Kahverenkli, yüksek plastisiteli silt ve killerin maksimum kuru yoğunlukları $1.69 \mathrm{~g} /$ $\mathrm{cm}^{3}$ ile $1.77 \mathrm{~g} / \mathrm{cm}^{3}$, optimum su içeriği ise \% 16 ile \% 23 arasında değişmektedir (Çizelge 1). Yeşilimsi gri siltli kumun (SM) maksimum kuru yoğunluğu $1.73 \mathrm{~g} / \mathrm{cm}^{3}$ olup, optimum su içeriği \% 10 olarak belirlenmiştir. Standard proktor moldunda optimum su içeriği ve maksimum kuru yoğunlukta sıkıştırılan kilin geçirimlilik katsayısı 
Ulamış, Kılıç

düşen seviyeli permametre deneyi ile belirlenmiş olup, $4.97 * 10^{-9} \mathrm{~cm} / \mathrm{s}$ ile $3.6 * 10^{-8} \mathrm{~cm} / \mathrm{s}$ arasinda değişmektedir ve geçirimsiz zemin sınıfindadır.
Siltli kumun geçirimlilik katsayısı ise $3.33 * 10^{-6}$ $\mathrm{cm} / \mathrm{s}$ olup, yarı geçirimlidir.

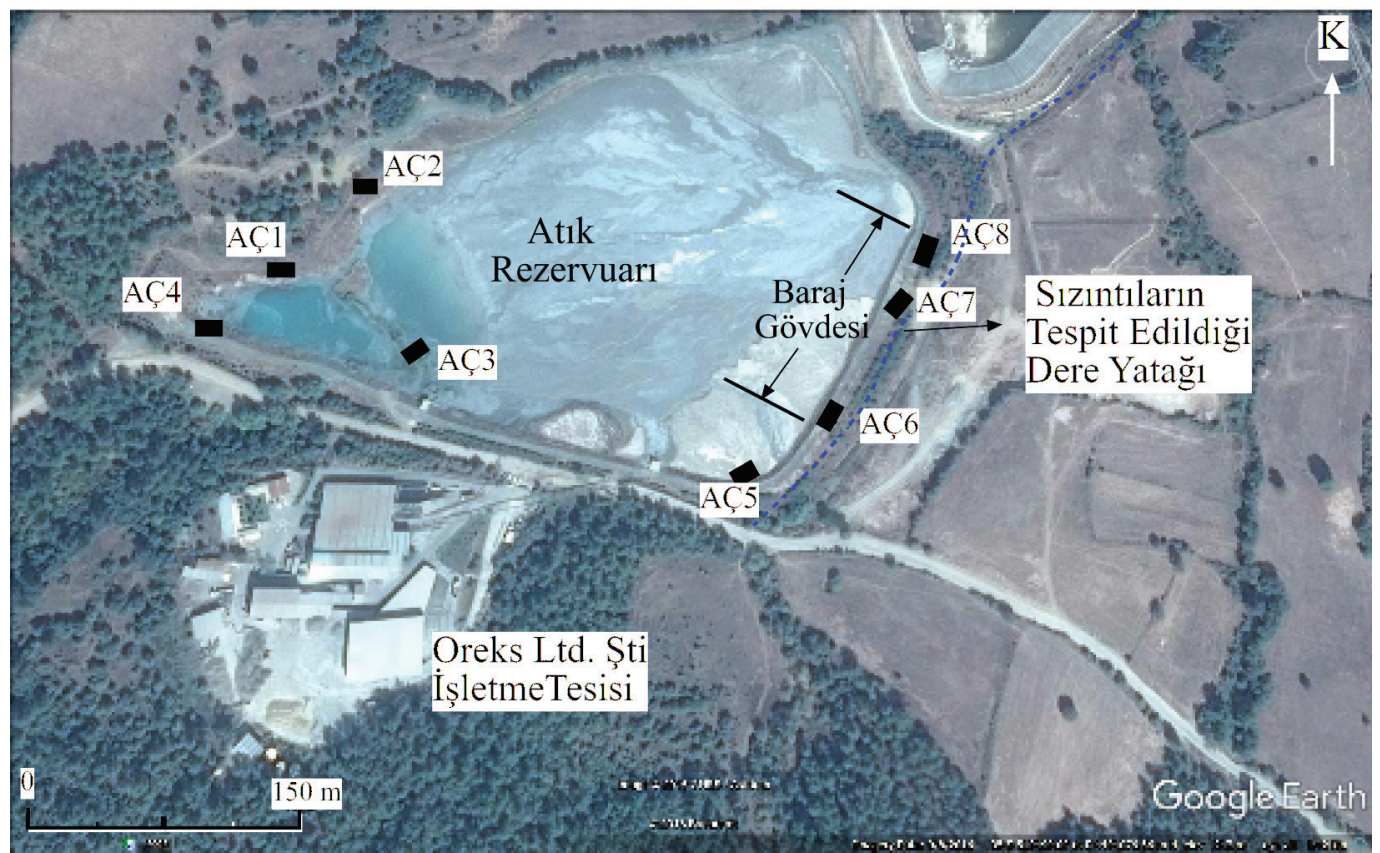

Şekil 2. Atık rezervuar alanı ve araştırma çukuru konumları.

Figure 2. Location of the tailing dam and trial pits.

Çizelge 1. Zemin örneklerinin derinlik, doğal su içeriği, sıkışma parametreleri ve geçirmlilik katsayıları.

Table 1. Depth, natural water content, compaction parameters and permeability coefficients of the soil samples.

\begin{tabular}{|c|c|c|c|c|c|c|}
\hline & Örnek & Derinlik, $\mathrm{m}$ & USCS & $\omega_{\mathrm{opt}}, \%$ & $\rho_{\mathrm{dmax}} \mathrm{g} / \mathrm{cm}^{3}$ & $\mathrm{k}, \mathrm{cm} / \mathrm{s}$ \\
\hline AÇ1 & S1 & 3.50 & $\mathrm{CH}$ & 21 & 1.72 & $4.97 \times 10^{-9}$ \\
\hline \multirow{3}{*}{$\mathrm{AÇ} 2$} & S1 & 1.75 & $\mathrm{CH}$ & 18 & 1.77 & $2.06 \times 10^{-8}$ \\
\hline & UD1 & 3.00 & $\mathrm{CH}$ & 23 & 1.76 & $3.68 \times 10^{-8}$ \\
\hline & UD2 & 4.00 & $\mathrm{CH}$ & & & - \\
\hline \multirow{2}{*}{ AÇ3 } & S1 & 1.75 & SM & 10 & 1.73 & $3.33 \times 10^{-6}$ \\
\hline & S2 & 3.50 & $\mathrm{CH}$ & 16 & 1.69 & $1.83 \times 10^{-8}$ \\
\hline AÇ4 & S1 & 3.50 & $\mathrm{CH}$ & - & & - \\
\hline AÇ7 & S1 & 5.50 & $\mathrm{CH}$ & - & & - \\
\hline
\end{tabular}




\section{BARAJ YERININ MÜHENDISLLIK JEOLOJISİ}

Rezervuar alanı; tabanda $30 \mathrm{~cm}$ kalınlıkta sıkıştırılmış kil ile geçirimsizlik sağlanarak, toplam alanı 4.16 hektar, atı depolama kapasitesi 285.000 ton olacak şekilde projelendirilmiştir (M\&T Müh. Ltd. Şti., 2005). Rezervuar kazısı öncesinde alanı güneybat1kuzeydoğu yönünde kesen dere drene edilmiş, fakat alüvyonun kaldırılmadığı anlaşılmıştır. Rezervuarın güney-güneybatısında açılan AÇ1, AÇ2, AÇ3 ve AÇ4 numaralı çukurlarda yüksek plastisiteli kahverengi kil içinde kalınlığı 30$50 \mathrm{~cm}$ arasında değişen yeşilimsi gri siltli kum bantları bulunmaktadır (Şekil 3). Eşyükselti eğrileri ve alanın geçmişteki uydu görüntülerinde rezervuarın inşa edileceği alanın doğusunda eski dere yatağı bulunmakta olup, burada açılan AÇ5, AÇ6, AÇ7 ve AÇ8 numaralı araştırma çukurlarında kalınlığı $50 \mathrm{~cm}$ ile $100 \mathrm{~cm}$ arasında değişen alüvyon belirlenmiştir. Baraj gövdesinin dolgusu da kuzey kesimlerde alüvyonun üzerinde bulunmaktadır (Şekil 3). İnceleme yapılan 2007 yılı Temmuz ve Ağustos aylarında araştırma çukurlarında yeraltı suyuna rastlanmamıştır. Baraj gövdesinin kuzey kesiminde mansap tarafında açılan AÇ6, AÇ7 ve AÇ8 numaralı çukurlarda baraj gövde dolgusu ile kahverenkli kil arasında kalan alüvyonda su kaçakları belirlenmiştir (Şekil 4).
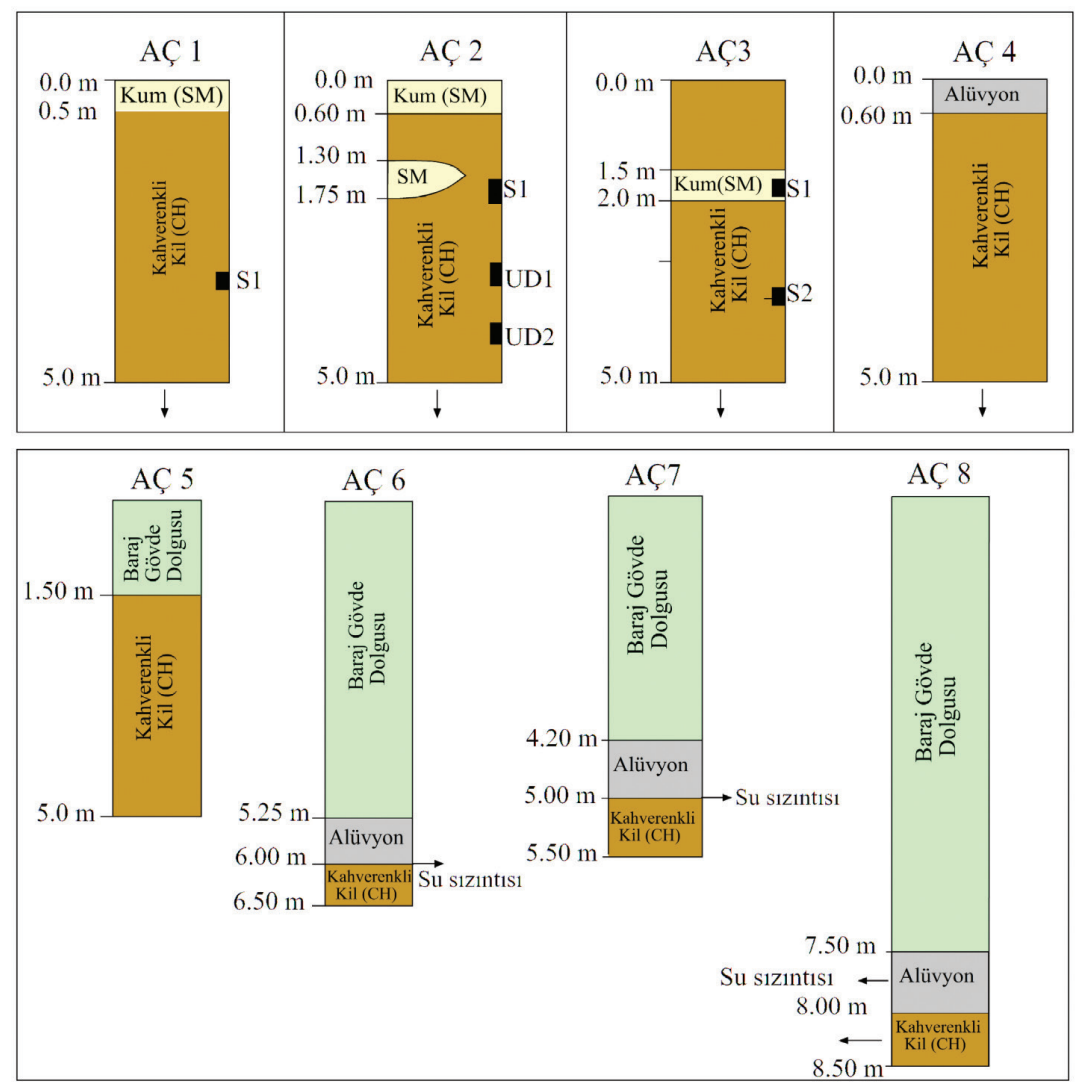

Şekil 3. Baraj rezervuarı ve gövdesinde açılan araştırma çukurlarının kesitleri.

Figure 3. Sections of the trial pits at the reservoir and dam site. 
Ulamış, Kılıç
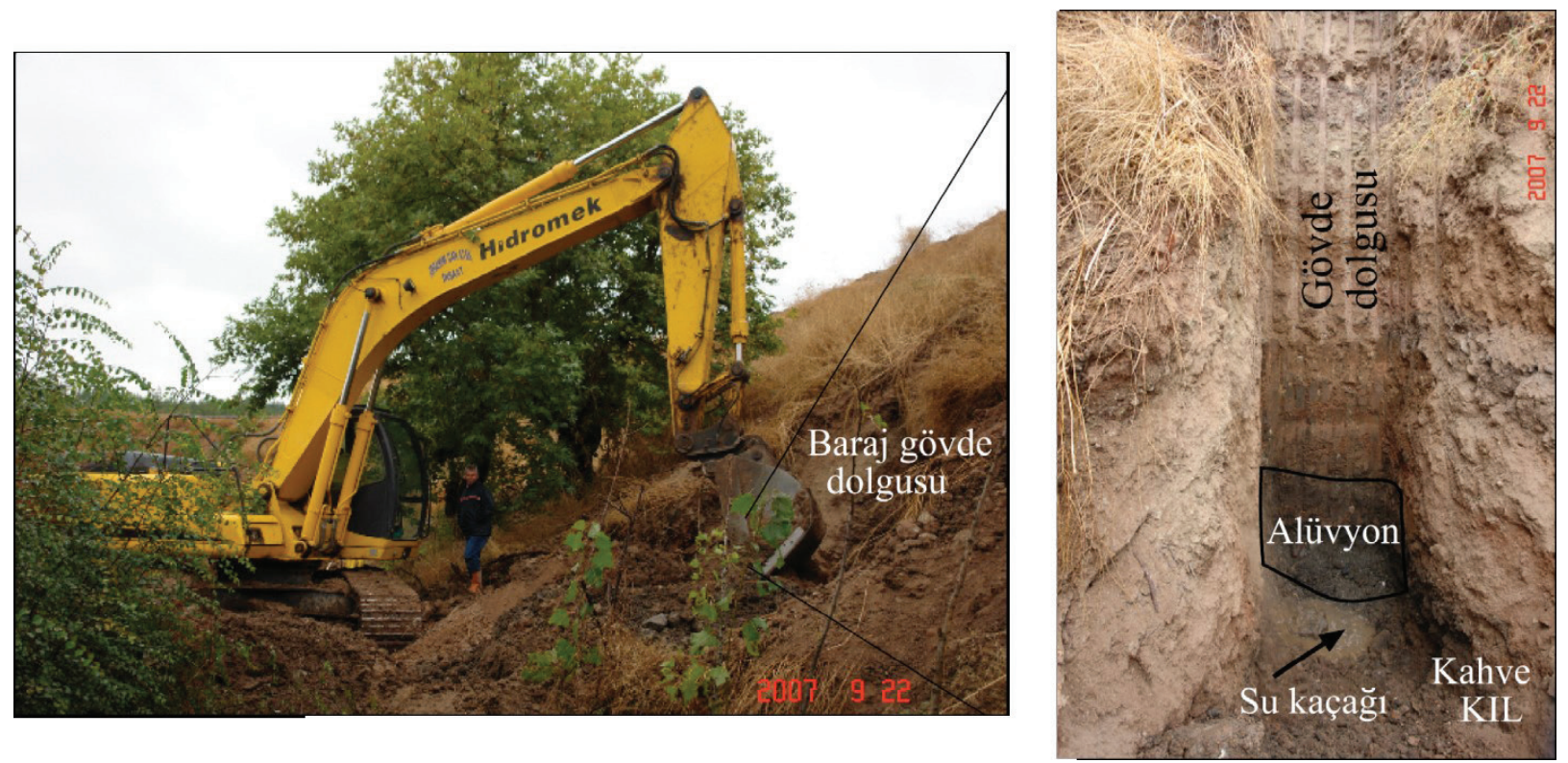

Şekil 4. Baraj gövde dolgusu ile kahverengi kil arasındaki alüvyonda su kaçağı.

Figure 4. Water seepage from the alluvium between the dam fill material and brown clay.

Rezervuar alanının çevresinde arazi incelemeleri yapılarak, özellikle alüvyon malzemenin bulunabileceği kesimler belirlenmeye çalışılmıştır. Eğim güneyden doğuya doğru azalmakta olup, inceleme alanı ile ilgili hazırlanan ÇED raporlarında tabandaki kil kaplamada geçirimlilik sorunu olmadığı belirtilmiştir. Rezervuar alanında KB-GD yönünde akan eski dere yatağındaki çakıllı, kumlu alüvyon kesim kil kaplamanın altında kalmış olup, üzerine baraj dolgusu inşaa edilmiştir. Zamanla kazılarak yerine sıkışmış malzeme yerleştirilmeyen alüvyondan kaplama üzerinde çökelen artık malzemeyi de doğudaki dereye doğru taşımaya başlamıştır.

\section{ATIK HAVUZUNUN ÇEVRESEL ETKILERİ}

Oreks Ltd. Şti. Cevher Zenginleştirme Tesisi'nde $\mathrm{Pb}-\mathrm{Zn}$ cevherinin kırma, eleme ve yıkama işlemlerinden çıkan atık su, kapalı borular ile baraj rezervuarına iletilmektedir. Katı atıkların boyutu en fazla $12 \mathrm{~mm}$ olup, su ile gelen atıklar rezervuar tabanında çökeltilmektedir. Yüzeyde durulan su ise işletmede kullanılmak üzere pompajla çekilerek tekrar tesise iletilmektedir. Baraj rezervuarında meydana gelen sızma ile baraj gövdesinin mansap tarafinda güneybat1kuzeydoğu yönünde akan dere içinde ağır metaller de içeren siyahımsı Pb-Zn çökelleri ile sar1-kahverengi demiroksit çökeltiler gözlenmiştir (Şekil 5a,b). Bu kirlilik deredeki canlı yaşamını olumsuz yönde etkilemektedir.

Baraj gövdesinin $100 \mathrm{~m}$ uzunluğundaki kesimi kazılarak geçirimsiz kil ile gövde dolgusu arasındaki alüvyonun temizlenmesi önerilmiştir. Gövdenin kaldırılan kesimi optimum su içeriği ve maksimum kuru yoğunlukta sıkıştırılıp imal edilmesi ile su kaçakları tamamıla önlenmiştir (K1lıç, 2007). Bu öneri doğrultusunda iyileştirme yapılması ve üst kotu 238-240 m arasında değişen 
gövdenin 255 m kotuna yükseltileceği 2013 tarihli ÇED raporunda belirtilmiştir (SimÇed, 2013). Bu sayede, rezervuardan kaçaklar önlenmiş ve çevresel etkileri önlenmiştir. Tesiste üretim halen devam etmektedir.

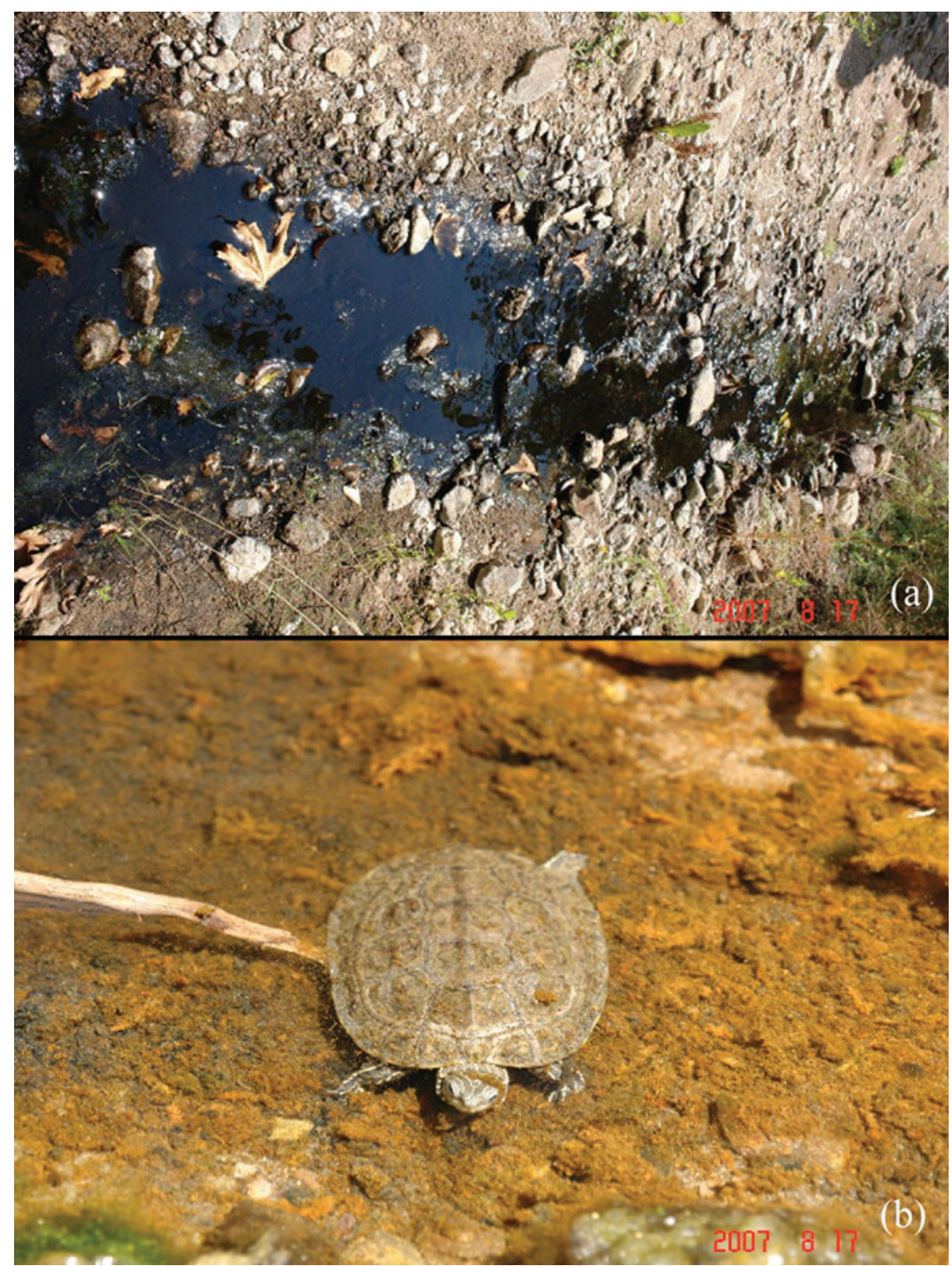

Şekil 5. Gövde mansabındaki dere yatağında çökelen ağır metal ve demiroksit (a) ile yaşam mücadelesi veren su kaplumbağası (b).

Figure 5. Heavy metal contamination and ferro-oxidation in the streem channel at downstream of the dam structure (a) and a turtle struggling in this environment (b). 
Ulamış, Kılıç

\section{SONUÇ VE ÖNERİLER}

Çanakkale ili, Yenice ilçesi, Kalkım beldesinde bulunan cevher zenginleştirme tesisindeki atık baraj rezervuarındaki kaçakların nedenlerini araştırmak amacı ile, baraj yerinin jeolojisi, zeminlerin fiziksel ve siniflama özellikleri ve geçirgenlik katsayısı incelenerek aşağıdaki sonuçlar elde edilmiştir.

Rezervuar alanı ve çevresindeki temel birim kahverengi katı kilden oluşmaktadır. Kalınlığ 50 cm'yi geçmeyen kum mercekleri eğimin azaldığ1 kesimde bulunmamakta olup, geçirimlilik sorunu yaratabileceği düşünülerek örnek alınmış ve yarı geçirimli olduğu tespit edilmiştir. Araştırma çukurlarında derinlikle beraber kumlu merceklerin görülmemesi de sizma problemine neden olmayacağını desteklemiştir.

Rezervuar alanının doğu kesimi hariç şevlerin topuklarında herhangi bir sızma tespit edilmemiştir. Araştırma çukurları özellikle baraj gövdesinde, şevlerinin en yüksek olduğu doğu kısımda ve eğimin azalmaya başladığ1 batı kısımda açılmıştır. Çukurların kazılması sırasında herhangi bir seviyeden yeraltı suyu gelişi belirlenmemiş olup, doğu kesimdeki AÇ6, AÇ7 ve AÇ8 numaralı çukurlarda katı kil ve grimsi renkli kumdan farklı olan eski alüvyon belirlenmiştir. AÇ6 numaralı çukur tam gövde üzerinde, AÇ7 ve AÇ8 ise gövdenin doğu şevlerinde, 1-2 m daha düşük kotlarda açılmıştır. AÇ6 numaralı çukurda alüvyonun bulunduğu seviyeden sızan su ile rezervuardaki suyun alt kotu yaklaşık aynı seviyededir. AÇ7 ve AÇ8 açılırken su sızıntısı gözlenmese de, kesilen birimler aynıdır.

Baraj gövdesinin kuzeyindeki dere yatağında, ağır metaller içeren siyahımsı çökeltiler ve kahverengi-sarımsı demiroksit çökeltilerine rastlanmıştır. İnceleme döneminde su kimyası için örnekleme imkanı olmamıştır.
Deredeki kirlilik seviyesinin belirlenmesi ve takibinin yapılabilmesi için sistematik su kimyası analizleri yapılması uygun olacaktır.

Baraj gövdesinin kuzey kesiminin 100 metrelik kısmının kaldırılarak optimum su içeriği ve maksimum kuru yoğunlukta sıkıştırılması ile su kaçaklarının önlenmesi mümkün olacaktır. Araştırma çukurlarında belirlenen geçirimsiz kahverengi kilin dolguda kullanılması uygun olacaktır.

\section{KAYNAKLAR}

Akıska, S., Demirela,G., Sayılı,S., 2013a. Geology, mineralogy and the $\mathrm{Pb}, \mathrm{S}$ isotope study of the Kalkım $\mathrm{Pb}-\mathrm{Zn} \pm \mathrm{Cu}$ deposits Biga Peninsula, NW Turkey. Journal of Geosciences, 58, 279-396.

Akıska, S., Sayılı, S., Demirela, G., 2013 b. Three-dimensional subsurface modeling of mineralization: a case study from the Handeresi (Çanakkale, NW Turkey) $\mathrm{Pb}-\mathrm{Zn}-\mathrm{Cu}$ deposit. Turkish Journal of Earth Sciences, 22, 574-587.

American Standards of Testing Materials (ASTM), 2012. Soil and Rock (I): D420 - D5876. Volume 04.08. $1830 \mathrm{p}$.

Anıl, M., 1984. Yenice (Arapuçandere -Kurttaş1Sofular ve Kalkım Handeresi) $\mathrm{Pb}-\mathrm{Zn}-\mathrm{Cu}$ cevherleşmelerinin köken sorunu ve Tersiyer volkanizmasıyla ilişkileri. Jeoloji Mühendisliği Dergisi, 20, 17-31.

Cedergren, H. R., 1989. Seepage, Drainage and Flow Nets. 3rd Ed. Wiley, NY, 254-291 p.

Dougherty, T. C., Hall, A.W., 1995. FAO Irrigation and Drainage. Paper 53. HR Wallingford, 106 p.

Erentöz, C., 1975. 1/500 000 Ölcekli Turkiye Jeoloji Haritasi. MTA Ankara (yayımlanmamış).

Ghobadi, M. H., Khanlari, G. R., Djalaly, H., 2005. Seepage problems in the right abutment of the Shahid Abbaspour dam, southern Iran. Engineering Geology, 82, 119-126. 
Gözler, Z., Ergül, E., Akçören, F., Genç, Ş., Akat, U., Acar, Ş. 1984. Çanakkale Boğazı doğusuMarmara Denizi güneyi-Bandırma-BalıkesirEdremit ve Ege Denizi arasındaki alanın jeolojisi ve kompilasyonu. MTA Derleme Rapor No: 7430, Balıkesir (yayımlanmamış).

Hilf, J. W., 1975. Compacted fill. Chapter 7. In: Foundation Engineering Handbook, Winterkorn and Fang, eds, Van Nostrand Reinhold, NY, 244311.

Holtz, R. D., 1989. NCHRP Synthesis of Highway Practice 147: Treatment of Problem Foundations for Highway Embankments. TR, NRC, Washington DC,72 p.

ICOLD (International Commission on Large Dams), 1981. Dams and the Environment, Bulletin 35 (http://www.icold-cigb.org/GB/publications/ bulletins.asp).

Johnson, A.W., Sallberg, J. R., 1960. Factors that influence field compaction of soils. Bulletin 272, HRB. NRC, Washington DC, 206 p.

Kılıç, R., 2007. Oreks Madencilik Ltd. Şti. Kalkım Flotasyon Tesisi Atık Baraj Yeri (Çanakkale, Yenice) Zeminlerinin Geçirgenlik Özellikleri. AÜ Döner Sermaye Rapor, 15 s (yayımlanmamış)

McGuffey, V. C., Bellatty, T. A., Haas, W.M., 1990. Environmental considerations. In: TRB Guide to Earthwork Construction. Chapter 8, 83-91 p.

M\&T Müh. Ltd. Şti., 2005. Oreks Madencilik Ltd. Şti. Maden Zenginleştirme Tesisi, Çanakkale İli, Yenice İlçesi, Kalkım Beldesi, Karaaydin Köyü Nihai Çed Raporu. 104 s (yayımlanmamış).
Orgün, Y., Gültekin, A. H., Önal, A., 2005. Geology, mineralogy and fluid inclusion data from the Arapucan $\mathrm{Pb}-\mathrm{Zn}-\mathrm{Cu}-\mathrm{Ag}$ deposit, Çanakkale, Turkey. Journal of Asian Earth Sciences, 25, 629-642.

Sharma, R. S., Al-Busaidi, T. S., 2001. Groundwater pollution due to a tailings dam. Engineering Geology, 60, 235-244.

Sim-Çed, Sicimoğlu Müh. İnş. Ltd. Şti., 2013. OREKS Madencilik Ltd. Şti. çinko, kurşun ve bakır zenginleştirme tesisi kapasite artırımı ve atık depo alanları projesi çevresel etki değerlendirmesi başvuru dosyası. $36 \mathrm{~s}$ (yayımlanmamış).

TRB (Transportation Research Board), 1990. Guide to Earthwork Construction. State of the Art Report, 8. Washington DC, $119 \mathrm{p}$.

TS 1900-1., 2006. İnşaat Mühendisliğinde Zemin Laboratuvar Deneyleri - Bölüm 1: Fiziksel Özelliklerin Tayini, 93 s, Ankara.

Tufan, A. E., 2003. Karaaydın Köyü (Yenice, Çanakkale) kurşun-çinko zuhurlarının jeolojisi, parajenezi ve oluşumu. Niğde Üniversitesi Mühendislik Bilimleri Dergisi, 7 (1- 2), 95-106.

Ulamış, K., Kılıç, R., Bilgehan, R. P., 2013. Atık barajlarında su kaçakları ve iyileştirme yöntemleri, Kalkım (Çanakkale) örneği. Baki Canik Su Medeniyeti Sempozyumu Bildiriler Kitab1, s.11, Aksaray.

Yilmaz, A., Atmaca, E., 2006. Environmental geological assessment of a solid waste disposal site: a case study in Sivas, Turkey. Environmental Geology, 50, 677-689. 
